\title{
AGENTES DEL ORDEN: REDES SOCIALES Y VIGILANCIA URBANA EN LIMA, 1890-1900
}

\author{
AGENTS OF ORDER: SOCIAL NETWORKS AND URBAN \\ SURVEILLANCE IN LIMA, 1890-1900
}

Luz Huertas Castillo*

\begin{abstract}
En Lima de fines del siglo XIX coexistieron dos formas de vigilancia urbana que se complementaban en la vida diaria, aunque ellas respondían a intereses distintos y a entes muchas veces vistos como antagónicos. Por un lado, la incipiente policía urbana ejerció un nivel de autoridad que, aunque limitado, era reconocido por la mayoría de los vecinos de la ciudad, en especial los de los sectores populares. Es importante resaltar que esta autoridad se ejerció a pesar de que estas fuerzas policiales tuvieron una organización deficiente, un presupuesto precario y dependían de un personal inestable y aún no profesionalizado. Por otro lado, las redes sociales desarrolladas por los vecinos y la población flotante de la ciudad mediante antiguas prácticas no oficiales de vigilancia permitieron a las clases medias y populares contar con un sistema de control social propio. Este sistema de control fue muchas veces más efectivo que el de la propia policía, la que dependía en gran medida de estas formas no oficiales de control. Estas dos formas de vigilancia permitieron tanto a ciudadanos como a policías ser agentes del orden en la ciudad.
\end{abstract}

Palabras claves: Policía, Lima, Callao, vigilancia, control social, redes sociales, orden urbano, siglo XIX.

In late-19th century Lima, two forms of surveillance coexisted and complemented each other in everyday life even though they responded to the interests of two distinct entities commonly seen as antagonistic. On the one hand, the incipient urban police of the capital city exercised a level of authority that, although limited, was recognized by most of the city's dwellers. The police managed to establish their authority despite the fact that this institution had a deficient organization, a precarious budget and an unstable and not yet professionalized personnel. On the other hand, the social networks that the city's dwellers developed through old and informal surveillance practices allowed the lower and middle classes to have a system of social control that was often more effective than the one of the police. In fact, the police depended to a large degree on those informal practices to do their job. These two forms of surveillance allowed both dwellers and police officers to be agents of order in the city.

Key words: Police, Lima, Callao, surveillance, social control, social networks, urban order, 19th century.

\section{Introducción}

Una tarde de julio de 1890 al regresar a su vivienda, el joven Belisario Heredia descubrió que la puerta del cuarto que alquilaba en el puerto del Callao, a pocos kilómetros de Lima, había sido dañada y varias de sus cosas habían desaparecido. Decidió entonces realizar las diligencias respectivas, siendo una de ellas el informar al agente de policía de la zona, el teniente Bocanegra, respecto de este hecho. Este agente del orden escuchó la denuncia de Belisario y decidió no hacer absolutamente nada; después de todo, la víctima del robo le había dicho que él mismo iría a la Intendencia de Policía a presentar la denuncia. Belisario hizo eso y más, ya que sabía de los lugares de compra y venta de objetos robados. Tras indagar en locales de préstamo cercanos y en un salón, logró identificar sus pertenencias y, también, al posible ladrón. Luego de solicitar ayuda a otro policía, Belisario recuperó sus pertenencias e hizo arrestar al presunto culpable (AGN, Poder Judicial, Causas Criminales, 1890, Legajo 522, Expediente 15) ${ }^{1}$.

La resolución de este caso se logró no solo por la iniciativa de la víctima quien con solo quince años de edad conocía ya los circuitos de la ilegalidad en ese puerto, sino también por la efectividad de las redes sociales y de información existentes dentro y fuera de dichos circuitos. Estas redes estaban conformadas por vecinos, prestamistas, porteras, dueños de bares, vigilantes informales y un sinnúmero de personas que recorrían las calles de Lima y Callao todos los días a fines del siglo XIX. Cuando estas personas participaban activamente de la vigilancia de la ciudad, cumplían el rol de agentes del orden y usaban sus propios criterios en la lucha contra

* Fairleigh Dickinson University, Nueva Jersey, EE.UU. Correo electrónico: lhuertas@fdu.edu 
la criminalidad y prácticas consideradas por ellos como peligrosas.

El creciente interés en el rol e impacto de formas oficiales y no oficiales de vigilancia urbana y su relación con las instituciones vinculadas al orden público viene generando ya espacios de discusión en los que se ha ido incorporando el análisis de la vigilancia como una práctica cultural en América Latina. Este interés se ha centrado sobre todo en períodos anteriores al de la profesionalización de las fuerzas policiales en las primeras décadas del siglo veinte o durante este proceso de transformación de la cultura e infraestructura policial. Esta perspectiva está ampliando las interpretaciones acerca del rol de la policía y las políticas de control social, temas que se abordaron inicialmente desde el punto de vista social e institucional y en las que se enfatizó una mirada dicotómica de la relación entre sociedad y Estado. La incorporación de una perspectiva cultural y la profundización de las investigaciones respecto de estos temas ha permitido que en los últimos años se genere una interpretación más crítica por el alcance del Estado y, sobre todo, de la interacción entre las fuerzas policiales y los habitantes de las principales urbes latinoamericanas -las que, con algunas excepciones, siguen acaparando atención de la mayoría de estos estudios- (Picato 2001a, Galeano 2010 2016, Hering 2010, Sirimarco 2010, Caimari 2017, Mauch 2017, Duffau 2018). Pablo Piccato, por ejemplo, ha identificado prácticas en las que convergieron los métodos de vigilancia del ciudadano de a pie y los de la propia gendarmería para el caso mexicano durante el Porfiriato. Esta convergencia fue el resultado de la incapacidad de una policía semiprofesional de lidiar con la criminalidad local, lo que permitió cierto nivel de negociación entre los vecinos y los gendarmes, una relación que demuestra que los policías tuvieron un rol más complejo que el de simples ejecutores de los proyectos de las élites (Piccato 2001a: 45). Esta cercanía también ha sido estudiada por Lila Caimari, quien ha analizado esta relación en conexión con casos de corrupción en Buenos Aires a inicios del siglo XX (Caimari 2017: 96-104).

Es importante resaltar que estos avances en la investigación del crimen y el control social han ido de la mano con la formulación de interpretaciones más amplias de estos conceptos, las mismas que se han alejado de posturas que privilegiaban al Estado como el productor de nociones y mecanismos de control social. Estas nuevas interpretaciones apuntan a identificar a todos los mecanismos y estrategias que surgen mediante formas de identificar actos o comportamientos que las personas consideran delictivos o peligrosos. En palabras de Herman Roodenburg y Pieter Spierenburg, estos mecanismos y estrategias se expresan en un sinnúmero de formas oficiales y no oficiales, desde las producidas a nivel personal hasta las impuestas por el Estado (Roodenburg y Spierenburg 2004: 147).

Este artículo busca incorporar a Lima en esta área de trabajo, ampliando y revisando algunos temas y conceptos presentados por Carlos Aguirre en sus investigaciones acerca de las prisiones, el control social y los estudios criminológicos en Perú (Aguirre 1998, 2005, 2008). Nuestro estudio señala que, lejos de tener el monopolio del control social en la capital de Perú, la policía compartió la responsabilidad de vigilar la ciudad con la propia gente que la habitaba. A fines del siglo XIX la policía urbana, en ese entonces conocida como la Guardia Civil, carecía de los recursos institucionales, políticos y económicos para ejercer un dominio efectivo y permanente sobre la población en el día a día. Estas carencias fueron el resultado de un prolongado desinterés de la clase política en realizar reformas policiales integrales y profundas, que fueran más allá de las necesidades inmediatas de los gobiernos de turno. Por su parte, los habitantes de la ciudad-limeños, provincianos y extranjerosinteractuaban con la misma por medio de las redes que establecían y reforzaban diariamente. Es con estas redes que era posible efectuar una forma no oficial de vigilancia en lugares públicos y privados que muchas veces era más efectiva y tenía mayor alcance que la de la propia policía. Esta forma de vigilancia, producto de la capacidad de agencia del poblador capitalino, no fue necesariamente excluyente o antagonizó con las fuerzas policiales. Muchas veces ambas formas de vigilancia se complementaron, logrando que intereses y formas de entender el orden social creados fuera del Estado $-\mathrm{y}$, por ello, de las élites políticas- influenciaran las prácticas de las instituciones estatales.

La existencia de esta relación entre formas oficiales y no oficiales de vigilancia no eclipsa o excluye otras formas de interacción entre la policía y pobladores en las que prevalecieron prácticas represivas. Por el contrario, consideramos que ambas muestran aspectos importantes de los cambios políticos y sociales que ocurrieron a lo largo del siglo XIX, en particular a fin de siglo, 
período central en este estudio debido a que en él se dio un renovado interés en la modernización de las políticas e instituciones oficiales de control social en Perú. Sin embargo, este estudio rechaza análisis que favorecen únicamente una visión de la policía como instrumento represivo del Estado o como un ente antagónico, externo y disociado de la sociedad durante este período. La relación entre estas dos formas de vigilancia claramente indica un interés en negociar e integrar nociones y prácticas de control social por parte tanto de policías como de los habitantes de Lima.

Para comprender estos espacios de negociación es importante considerar, en primer lugar, que la policía está lejos de ser una institución monolítica. Metodológicamente, nuestro análisis parte de una interpretación de la policía como una institución heterogénea que, como bien indica Diego Galeano, puede entenderse también como "un conglomerado complejo de diversas áreas de trabajo [...] que no pueden ser subsumidas a ninguna cultura común" y que además contienen perspectivas distintas acerca del propio quehacer policial (Galeano 2011: 188). A esta definición, nuestro estudio añade una perspectiva que examina a esta institución además como una entidad en la que coexistieron varias formas de entender el poder del Estado, la autoridad, y el orden y, sobre todo, cuya jerarquía institucional estaba profundamente ligada a las jerarquías de clase que dominaban a la sociedad peruana de ese entonces. En este sentido, la policía en la que nos enfocaremos no es la de las altas jefaturas o la que se comunicaba directamente con el Ministerio de Gobierno y Policía, hoy del Interior, sino el segmento conformado por los policías que recorrían la ciudad diariamente.

Respecto de las prácticas de vigilancia que existieron fuera del Estado, las que nos interesan son las formas de microvigilancia que emergieron como parte de los mecanismos de control desarrollados por sectores populares, las que interpretamos usando el concepto desarrollado por T. Monahan como "constitutivas de conocimiento, experiencias y relaciones" fundamentales en las interacciones diarias en la ciudad (Monahan 2011:496). Este estudio examina dichas interacciones como parte de lo rutinario y desde una historia de la vida diaria que permite reconstruir patrones de comportamiento en los que emergen intereses y estrategias particulares (Steege, Stuart Bergerson, Healy y Swett 2008) $)^{2}$.
El análisis de documentos pertenecientes a expedientes de Causas Criminales, así como correspondencia producida por la Intendencia y la Prefectura de Lima en su mayoría ubicados en el Archivo General de la Nación (AGN) ha permitido examinar dichos patrones aunque limitadamente y con un filtro institucional. Complementariamente, se han examinado memorias de ministros, prefectos e intendentes, manuales de policía y reglamentos que forman parte del fondo documental de la Biblioteca del Congreso de la República del Perú y la Biblioteca Nacional del Perú.

\section{La policía y la ciudad}

Los guardias que recorrían la ciudad capital diariamente durante la década de 1890 debieron haber tenido muy presente el carácter efímero e inestable de su trabajo. Pertenecer a la "fuerza pública" en ese entonces no era motivo de tranquilidad, en particular si uno tenía el rango de guardia, es decir, el último eslabón de la larga cadena de comando que terminaba en el puesto de Ministro de Gobierno y Policía. Paradójicamente, el puesto de ministro también era altamente inestable (Huertas 2015: 390$)^{3}$. Ambos representantes del Estado, uno en la calle asignada y el otro en el sillón ministerial estaban expuestos a los cambios sinuosos de la política peruana que usualmente producían grandes reducciones de personal en las comisarías y crisis en los gabinetes ministeriales. Mientras que, al dejar su puesto, el ministro probablemente terminaría ocupando la jefatura de otro ministerio o entidad pública o probando suerte con alguna candidatura, el guardia tendría que ejercer un segundo oficio, al que, si era necesario, recurría fuera de sus horas laborales para complementar su salario (Huertas 2015: 175-176). Además, el guardia que vigilaba las calles de Lima ejercía un oficio para el que no había sido entrenado y del que podía despedirse con facilidad ya sea debido a despidos arbitrarios, por iniciativa propia - para evitar castigos por faltas cometidas o porque ser policía ya no le resultaba rentable-, o por haber quedado incapacitado para la labor policial.

En cualquier caso, las comisarías de Lima sufrían de una carencia crónica de personal por estas tres razones, pero estaban sujetas a los designios del poder ejecutivo, los que usualmente también afectaban negativamente a sus presupuestos, por lo que recurrían a estrategias poco ortodoxas para 
solucionar este problema como, por ejemplo, a la contratación de guardias que no cumplían con los mínimos requisitos para formar parte de la Guardia Civil o la recontratación de guardias que habían sido expulsados de otras comisarías -o de ellas mismas- por "viciosos" o "inadecuados para el servicio" (Huertas 2015: 161). El personal policial a este nivel, entonces, era altamente irregular y fluido; una situación similar a la que Viviana Barry ha descrito para el caso de Buenos Aires durante el mismo período (Barry 2010: 2). Además, raramente las comisarías mantenían registros consistentes y detallados de sus guardias (lo que facilitaba la recontratación de personal inadecuado), al punto de que a los comisarios se les hacía difícil identificar a antiguos policías cuando su presencia era requerida por algún juez. Lima, en este sentido, estaba lejos de ser un caso único en la región. Las policías de Buenos Aires, Ciudad de México, Montevideo y Porto Alegre tuvieron problemas similares (Lila Caimari 2017, Pablo Piccato 2001a, Nicolás Duffau 2018 y Claudia Mauch 2017, respectivamente). En todos estos casos, así como en Lima, la calidad y cantidad del personal policial afectaron la reputación de esta institución y de sus miembros (en particular la de los policías que patrullaban las calles) así como su capacidad de brindar un servicio oportuno y eficiente.

Durante la década de 1890, la principal reforma policial efectuada por el gobierno (1895) incrementó los problemas relacionados a la escasez de personal, ya que, aunque aumentó el personal administrativo de la Intendencia de Lima, redujo al personal de vigilancia urbana (Ministerio de Gobierno y Policía $1896)^{4}$. Entre 1890 y 1910 , aproximadamente setecientos hombres en promedio, incluidos oficiales, patrullaban la ciudad, cuya población sobrepasaba los cien mil habitantes. Aunque en teoría la ratio policía-habitantes no estaba lejos de las de ciudades como Buenos Aires o Santiago de Chile, la constante fluctuación del personal y la inadecuada distribución de guardias afianzaron el carácter ineficiente del servicio (Tirado 1898: 31, Ministerio de Gobierno y Policía 1899:Anexo N.15, Ballvé 1900: 314)5.

Otro aspecto a tomar en cuenta que estaba profundamente relacionado con la fluctuación y calidad del personal policial fue la falta de preparación de los guardias y el escaso salario que estos recibían. El Perú no tuvo una academia o escuela de policía propiamente dicha hasta la década de 1920, a diferencia de Argentina (1906) y Chile (1908) que promovieron la profesionalización temprana de sus fuerzas policiales. A inicios de 1890, la preparación de los guardias dependió de un sistema inorgánico promovido personalmente por el Intendente de Lima, Pedro E. Muñiz, quien intentó modernizar a la policía de la capital incorporando conocimientos que había adquirido en Europa y que implementó principalmente al crear la morgue de Lima (1891) y la Sección de Identificación y Estadística (1892) (Aguirre 2005: 69, Huertas 2015: 145-146). Muñiz trató de solucionar la falta de una escuela de policía con lo que se denominaba "academia de instrucción". Esta academia, de acuerdo con el reglamento de la Guardia Civil de 1889, obligaba a cada comisaría a instruir a sus guardias por lo menos por dos horas durante el retén (AGN, Prefectura de Lima, 3.9.5.1.15.1.2.4, Director de Policía al Prefecto de Lima, Setiembre 2, 1889; Muñiz 1892). Aunque el Intendente intentó homogenizar el contenido de estas sesiones, las comisarías difícilmente podían coordinar lo que se impartía en dichas academias y, aún más, que la instrucción dada a los guardias fuese constante ${ }^{6}$.

Como se podía esperar, el guardia que vigilaba la ciudad estaba poco preparado para lidiar con el quehacer policial en las calles, el que no solo incluía combatir la criminalidad y evitar el desorden. Usualmente ese guardia, además, debía colaborar con las actividades de fiscalización de la municipalidad, verificar los trabajos de limpieza de la zona asignada, asistir a los bomberos en casos de siniestros, asistir y acompañar heridos a hospitales o boticas, socorrer a infantes abandonados, entre otras labores ${ }^{7}$. Aun cuando los guardias debían intervenir frente a un crimen, las metodologías usadas por ellos usualmente dejaban mucho que desear. Por ejemplo, un método particularmente problemático al efectuar un arresto era el traslado de un sospechoso de puesto en puesto desde el punto donde se efectuó su detención hasta la comisaría más cercana. Debido a que los guardias no podían abandonar sus puestos (que idealmente debían cubrir solo unas cuadras), estos debían conducir al sospechoso hasta el siguiente punto e informar al guardia asignado respecto del caso, quien a su vez tenía que repetir el procedimiento hasta que le tocase el turno al guardia ubicado más cerca de la comisaría. En teoría el primer guardia debía informar a un superior acerca de la causa del arresto e identificar al sospechoso. Sin embargo, debido a la falta de personal, a su mala distribución y, también, a la negligencia de guardias y oficiales, en la 
práctica esto no siempre ocurría (Lira 1902: XVI), por lo que el arresto podía terminar convirtiéndose en una cadena de confusión en la que el último guardia recibía información errónea de la causa del arresto y la identidad del sospechoso (Huertas 2015: 224-226).

Este método no fue un invento de la creativa policía de Lima. Según Pablo Piccato los gendarmes de Ciudad de México emplearon el mismo procedimiento, el que podía ser más o menos exitoso dependiendo de si los gendarmes tenían una buena relación con los vecinos, ya que entonces podían contar con su apoyo en su trayecto al siguiente puesto (Piccato 2010a: 43-44). Para el caso de Lima, no era poco común encontrar a vecinos, víctimas, o denunciantes acompañando a los guardias para asegurarse de que el arresto fuese efectivo. Aún más, en 249 juicios de causas criminales analizados en los que se describe la participación de la policía en forma de arrestos entre 1890 y 1911, más del setenta por cierto muestra que los arrestos se efectuaron por iniciativa de los vecinos y no por la de la policía (AGN, Poder Judicial, Causas Criminales, legajos 515 a 530 (1890-1891), 600 a 602 (1895), 7 a 11 (1900), 33 a 38 (1905), and 49 a $52(1910))^{8}$.

\section{Vigilancias y agentes del orden}

Es decir, la mayoría de estos juicios se iniciaron como resultado de la vigilancia de los vecinos de la ciudad, quienes, al hacer uso de la policía, intervinieron en la construcción de criterios de orden, seguridad, y control social. Es posible resaltar que las clases populares participaron activamente en este proceso, lo que cuestiona la narrativa historiográfica en la que ha predominado una caracterización de este sector social únicamente como víctima de las políticas e instituciones del Estado, las que, bajo esta perspectiva, parecen tener siempre el monopolio de los criterios que definen lo que es o no un crimen o delito (Piccato 2000a: 11). En este sentido, nuestro análisis coincide con el de Michael C. Scardaville quien en su estudio acerca de México colonial argumenta que la clase trabajadora hizo uso activo del sistema de justicia para resolver disputas que ellos no podían solucionar en otras formas, al punto de que la mayoría de los arrestos solicitados se originaron en este sector (Scardaville 2000: 7).

Esta activa participación de los sectores populares se efectuó gracias a los mecanismos de vigilancia que ellos mismos desarrollaron mediante experiencias con la ciudad. La socialización y desarrollo del conocimiento producto de esas experiencias fue posible por redes sociales en las que se compartían, circulaban y construían nociones y estrategias de seguridad en el día a día. Es indudable que intereses particulares también influenciaron estos criterios. Sin embargo, también es evidente que estos mecanismos dependían de la solidaridad y sentido de comunidad de los vecinos. Asimismo, sería erróneo argumentar que estas estrategias surgieron debido a la ineficiencia policial o en oposición al quehacer policial. Más bien ellas habrían sido el producto de una cultura de vigilancia de larga data relacionada con una forma íntima de entender la ciudad por medio de relaciones interpersonales creadas cotidianamente.

Bajo esta perspectiva, el guardia asignado a una calle representaba una de muchas personas -y recursos- a los que se podía recurrir en caso necesario, por lo que podía ser ventajoso mantener cierto nivel de familiaridad con ellos. Por el lado de los guardias, esta familiaridad también podía ser ventajosa, sobre todo si consideramos que la falta de estabilidad laboral y las precarias condiciones laborales a las que estaban sujetos podían demandarles un cambio de rubro laboral en cualquier momento. De hecho, el que guardias interactuasen con vecinos de barrios populares más allá que a nivel profesional era duramente criticado por las clases medias y altas, pero esta interacción parecía ser a veces inevitable, ya que los guardias tendían a residir en estos barrios (Huertas 2015: 170-173).

Dentro de este contexto, los juicios de causas criminales que se iniciaron como consecuencia de la vigilancia de los vecinos revelan, por ejemplo, que una forma común de solicitar la intervención de un guardia era mostrando lo que en ese entonces se conocía como "orden de detención" que era un papel otorgado por la Intendencia que autorizaba a un guardia a detener a un individuo.

Cuando la identidad de un sospechoso era conocida, la parte agraviada podía ir a la Intendencia a solicitar este documento. Las fuentes revisadas no muestran cuán riguroso era el proceso para obtener la orden o si las autoridades solicitaban pruebas del delito o la falta por la que se requería la detención de la persona en cuestión. Lo que sí es claro es que, al parecer, estas órdenes no eran difíciles de adquirir. Así, cualquier persona que poseía una orden de detención tenía autorización oficial para solicitar un arresto, el que era llevado 


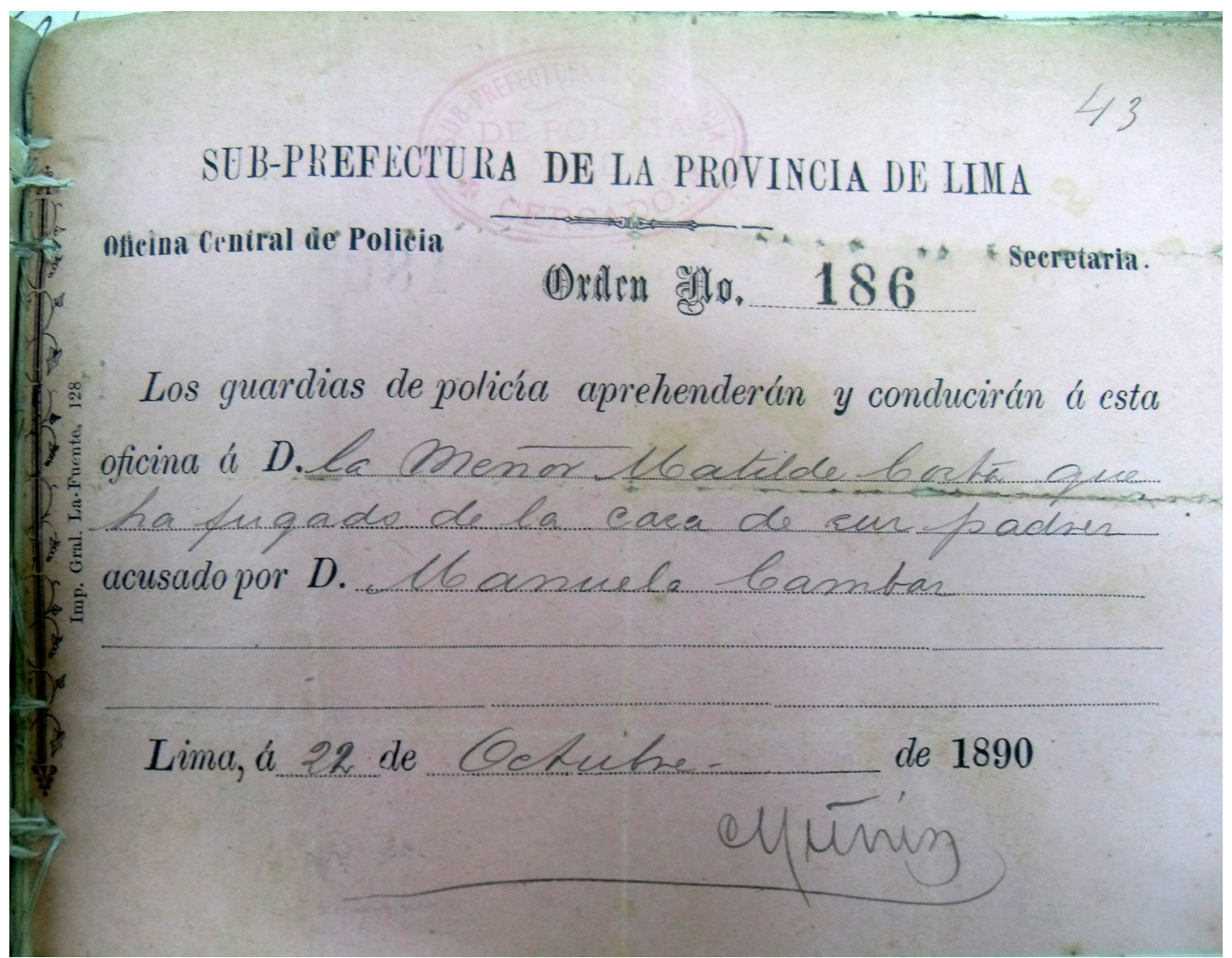

Figura 1. Orden de Detención N. 186 (1890).

Fuente: "Caso contra José Brondi, acusado de seducción, secuestro, y violación” (AGN, Poder Judicial, Causas Criminales, 1890, Legajo 524, Expediente 4).

a cabo por los guardias usualmente sin solicitar más información acerca del presunto agresor o el delito que se le imputaba. De hecho, para algunas autoridades estos documentos ayudaban a acelerar los procesos de detención sin dar lugar a confusión respecto de quién era la parte agraviada y a quién se debía arrestar. Es importante resaltar que al otorgar estas órdenes la Intendencia reconocía, de paso, la capacidad de los ciudadanos de realizar sus propias investigaciones y seguimientos $\mathrm{y}$, asimismo, avalaba el resultado de los mismos (Huertas 2015) ${ }^{9}$.

Las razones por las que vecinos usualmente solicitaban estas órdenes incluyen: robos, violencia doméstica, asaltos, y hasta padres que trataban de ubicar -y castigar-a sus hijos. Estas órdenes podían usarse fácilmente de forma abusiva en la resolución de conflictos personales. Sin embargo, no hemos encontrado evidencia de que este tipo de práctica predominara durante el período estudiado, quizá debido a que las órdenes de detención examinadas son solo las que llegaron a usarse como pruebas en juicios de causas criminales. Más bien, lo que resalta en los juicios analizados es la demanda común de este recurso en particular en casos de lesiones.

Un caso ilustrativo que muestra aspectos importantes del uso de estos documentos y el reconocimiento de la vigilancia no oficial del ciudadano de a pie por parte de las autoridades es el de la planchadora Beatriz Iribarren y la vendedora de camarones Mercedes Bonilla, quienes una noche de diciembre de 1894 se pelearon hasta que Beatriz logró inferir varios cortes en la cara a Mercedes. De acuerdo con Beatriz, ambas se conocían, pero su relación no se mantenía en buenos términos por mucho tiempo. La noche de los hechos, Mercedes le pidió a Beatriz que abandonara su casa, donde un grupo de personas había estado celebrando. Humillada, Mercedes se fue, pero regresó al poco 
tiempo a increparle a Beatriz su actitud. Pronto, la conversación de convirtió en discusión, y la discusión en pelea. Después del incidente, de acuerdo con el testimonio de Mercedes, ella se quejó con la policía del ataque y solicitó una orden de detención "pero esta [Beatriz] abusando de la falta de policía que en esa fecha se dejaba notar en la ciudad, se burlaba de mí saliéndome frecuentemente al encuentro en los lugares donde tenía seguridad de no poder ser aprendida..." (AGN, Poder Judicial, Causas Criminales, 1895, Legajo 601, Expediente 21 , enero 21$)^{10}$. Después de dos meses de intentar efectuar la aprehensión, Mercedes logró hacer arrestar a Beatriz, quien posteriormente alegó haber actuado violentamente porque había ingerido demasiado alcohol la noche de los hechos, una estrategia comúnmente usada en ese entonces. Por su parte, el guardia que arrestó a Beatriz declaró que no podía brindar ninguna información de la acusada o el caso porque solo procedió "á cumplir la orden [de arrestar a Beatriz]... en mérito de una orden escrita del Señor Sub Prefecto, que al efecto mostró la agraviada..." (AGN, Poder Judicial, Causas Criminales, 1895, Legajo 601, Expediente 21, abril 20, folio 20). De esta forma, el testimonio del guardia Suárez claramente indica que él solo se limitó a concluir un proceso en el que la definición del acto delictivo -aunque sancionado por las autoridades- así como el seguimiento al infractor se iniciaron por agentes externos al Estado.

El caso de Beatriz y Mercedes tiene elementos comunes a otros en los que la acción policial simplemente fue la conclusión de un proceso definido por la agencia de la gente. Varios casos en los que se requirió el testimonio de guardias muestran que era usual para los vecinos enviar a uno de los muchachos del barrio a llamar al celador cuando ocurría algún incidente. Otros casos muestran la existencia de un nivel intermedio de vigilancia en la que una persona era la encargada de indagar y determinar si era necesaria la presencia de un guardia. Esta forma de microvigilancia emergió en lugares donde convergieron formas de solidaridad y escrutinio y en donde la necesidad de seguridad dio lugar a la legitimación de estos agentes del orden. Un caso poco estudiado pero que tiene elementos importantes para entender estas formas de microvigilancia es el de las porteras y porteros de los callejones de la ciudad, espacios "privilegiados para la socialización de la población popular de Lima" a los que Alicia del Águila ha denominado "ciudades dentro de la ciudad" (Del Águila, 1997: 58-59) ${ }^{11}$. Cuando los había, los porteros cumplían un rol que era, al parecer, entendido y respetado por los guardias, lo que de cierta manera reforzaba su autoridad.

Habría que indagar más respecto de estos agentes para poder evaluar hasta qué nivel ellos eran conscientes del impacto de sus roles o de su propia autoridad. En City of Suspects, por ejemplo, Piccato interpreta el rol de las porteras mexicanas como la "primera línea de defensa" en la prevención de robos, ya que ellas podían llamar a la policía y "hasta detener a sospechosos" (Piccato, 2001a: 150, 2001b: 241). Para el caso de Lima, varios juicios muestran que las porteras y porteros limeños tuvieron atribuciones similares a los de sus pares mexicanos y eran vistos por sus vecinos como un primer recurso en casos de delitos contra la propiedad y la persona. Los porteros tendían a vivir en los callejones que vigilaban, por lo que manejaban información privilegiada de las personas que vivían allí. Sin embargo, el alcance de su labor dependía, de hecho, de la colaboración entre ellos y sus vecinos (Huertas, 2015), como lo demuestra un incidente ocurrido en un callejón de la calle Siete Pecados del Cuartel III, el que estaba ubicado al Este de la ciudad, en donde, en junio de 1905, una inquilina informó a la portera que un hombre ebrio había entrado al callejón y había tratado de abrir violentamente la puerta de uno de los cuartos. Esa vecina sabía que la persona que habitaba dicho cuarto no se encontraba en casa, pero ella había autorizado a la portera a llamar a la policía en caso de que ese hombre apareciese de nuevo, hiciera algún escándalo o se comportara inadecuadamente. Al enterarse de lo sucedido, la portera llamó al policía asignado a su calle y le indicó que, aun cuando el sospechoso alegaba ser familiar de la vecina, él no vivía ahí y, además, había roto el candado que aseguraba la puerta. La palabra de la portera fue suficiente para el policía, quien procedió a realizar el arresto (AGN, Poder Judicial, Causas Criminales, 1905, Legajo 35, Expediente 1, febrero 24).

Varios otros casos muestran que los porteros y porteras actuaban siguiendo sus propios criterios aun cuando estos no estaban en sincronía con los de sus vecinos agraviados, quienes a veces evitaban la intervención de la policía o simplemente no podían solicitar su ayuda por estar incapacitados para ello. Esto quiere decir que, en ciertas situaciones, la definición de un acto como delito dependía únicamente del punto de vista de este agente. Asimismo, 
su capacidad de vigilancia tenía más alcance que la de los guardias -que a menudo escaseaban-, ya que tenían plena potestad de intervenir en el espacio privado. En este sentido, la rápida intervención de estos agentes podía evitar tragedias, en particular en casos de violencia doméstica y tentativas de feminicidio, como sucedió con Gregoria García en 1890, quien harta de las golpizas que le propinaba su pareja, Cayetano Salva, decidió huir y pedir ayuda a un familiar. Cayetano la siguió y cuando la encontró, la atacó, llegando a golpearla con un objeto cortante que le causó varias heridas. El escándalo producido por la pelea alertó al portero del lugar quien llamó a la policía y ayudó que se realizase el arresto de Cayetano (AGN, Poder Judicial, Causas Criminales, 1890, Legajo 529, Expediente 6, octubre 11). De manera similar, años más tarde, el rápido accionar de un portero pudo haber salvado la vida de Manuel Aparicio, quien había sido atacado por su conviviente con una botella estando ella en estado de ebriedad. Al parecer Manuel se limitó a lavar la herida, pero cuando el portero se cercioró de la situación, decidió dar aviso a las autoridades. Aun cuando Manuel se mostró renuente a presentar cargos contra ella porque "lo hizo mareada", él tuvo que ser llevado al hospital porque el corte le originó una hemorragia (AGN, Poder Judicial, Causas Criminales, 1900, Legajo 10, Expediente 8, enero 31).

Estos casos muestran que la labor de los porteros era esencial para mantener la seguridad en estos espacios, aunque las autoridades tendían a invisibilizarla al enfatizar en documentos oficiales solo la acción de los guardias que ejecutaban los arrestos. En los callejones de la ciudad, sin embargo, las nociones de orden y seguridad eran construidas y redefinidas por ambas partes. Es admisible resaltar que los casos que llegaron a filtrarse al sistema judicial y que generaron juicios fueron solo una fracción de los muchos incidentes en los que estos agentes debieron haber intervenido; al igual que los guardias de la ciudad, cuyas intervenciones no siempre generaron arrestos (Huertas, 2015: 232-233).

Fuera de los callejones de la capital también era posible encontrar recursos para luchar contra la inseguridad aun sin tener que recurrir a la policía, en particular en casos de robos. Mientras que las clases acomodadas tendían a buscar la intervención directa del Intendente o de alguien aún más influyente cuando eran víctimas de crímenes contra la propiedad, las clases populares debían o contentarse con la capacidad de indagación de los policías y del personal de las comisarías o tratar de realizar ellos mismos las investigaciones necesarias para recuperar sus bienes, como en el caso de Belisario Heredia, el que comentamos al inicio de este artículo. Algunos factores que contribuyeron a incentivar la proactividad de las víctimas de robo fueron la escasez o poca disponibilidad del personal policial, la poca confianza en la capacidad de investigación de la Intendencia y las comisarías y la falta crónica de recursos con la que tenía que lidiar la policía.

De hecho la Intendencia de Lima trató de mejorar su Sección de Investigación, pero usualmente los resultados de sus investigaciones eran mediocres aun en casos simples, como cuando el propio jefe de esta oficina, al comunicar a su superior los avances de una investigación, confesó que "a pesar de las minuciosas pesquisas que ordené se practicaran no se pudo descubrir nada hasta ayer que regresó Schutti [la víctima del robo] manifestando que había encontrado parte de la ropa que le robaron, vendida en una casa de compra y venta" (AGN, Poder Judicial, Causas Criminales, 1905, Legajo 35, Expediente 2, Marzo 14) ${ }^{12}$.

La cotidianidad con la que la policía emitía este tipo de respuestas afianzó actitudes de los vecinos dirigidas al uso de recursos para la resolución de sus propios casos. En ese sentido, los juicios de causas criminales revelan algunas estrategias usadas durante este período en las que predomina, por ejemplo, la búsqueda de información en circuitos vinculados al mercado negro de Lima y Callao. Al parecer, durante este período, la línea de división entre el mercado negro y el legal no era tan clara como se ha creído y el fácil acceso a estos circuitos ayudó a establecer una línea de acción a priori en la que recorrer casas de compra y venta de artículos usados, así como casas de empeño o pignoración era una primera acción a tomar. Por intermedio del personal que trabajaba en estos lugares, con suerte, uno podía adquirir información del paradero de sus objetos robados y de la persona que los ofreció. En el caso de que estos se hallasen, el siguiente paso era demostrar la culpabilidad del sospechoso, lo que era posible si se hallaban los recibos de pignoración entre sus pertenencias ${ }^{13}$. Para dar este paso, sin embargo, la parte interesada debía recurrir a la policía, quien con la información proporcionada por la víctima y testigos podía registrar la vivienda del presunto ladrón. 
Los policías tendían usar estrategias similares en sus investigaciones, en especial cuando los casos se complicaban como cuando los recibos de pignoración eran vendidos a terceros, pero aún en esas circunstancias también vemos a vecinos continuar sus propias indagaciones. En este proceso, la colaboración de los dependientes de los negocios involucrados era fundamental para las partes interesadas, pero aún más importante era que los propios dependientes iniciasen sus investigaciones cuando existía la sospecha de que los objetos ofertados fuesen robados. En el caso de que les importase el origen de los bienes ofrecidos, ellos también hacían uso de las redes de información y de la mirada vigilante de policías $\mathrm{y}$, sobre todo, de los vecinos.

\section{Conclusiones}

Tanto en los casos en donde la presunta víctima debía lidiar con el mercado negro de Lima como en los de las porteras y porteros de los callejones limeños, así como en los que muestran el uso de las órdenes de detención se observa una forma de entender la vigilancia como una potestad del poblador capitalino y como una expresión de las dinámicas sociales creadas en una ciudad en la que todavía era posible interactuar íntimamente con el entorno. Las estrategias de microvigilancia descritas en este texto emergieron por medio de interacciones diarias y gracias a agentes externos al Estado, quienes contribuyeron a definir qué era o no un delito. Estas estrategias, así como el rol de estos agentes coexistieron y muchas veces complementaron formas de vigilancia oficiales establecidas a partir del Estado -y viceversa-, cuyo principal representante en las calles, el guardia, estaba lejos de poder hacer de su institución ese ente "omnipresente" que Michel Foucault describiese en Vigilar y Castigar.

El análisis de estas estrategias y agentes en este artículo no ha buscado elucidar todas las formas y expresiones de estas vigilancias. En todo caso, el principal resultado de este análisis es la formulación de nuevas preguntas que solo pueden ser respondidas mediante la investigación y el diálogo académico, como, por ejemplo, ¿qué otras formas de interacción existieron entre los guardias de la ciudad y los vecinos?, ¿qué cambios sufrieron las formas de vigilancia no oficiales a lo largo de la época colonial y la temprana república?, ¿los mecanismos de vigilancia no oficiales han dejado de ser esenciales para el cumplimiento de la labor policial?, si es así ¿cuándo ocurrió dicho cambio?, entre otras preguntas.

Resulta interesante resaltar que en la documentación examinada se percibe también la existencia de otros agentes del orden en espacios públicos en los que predominaban formas distintas de interacción a las descritas aquí. Asimismo, habría que plantearse de qué manera estas estrategias movilizaron o no nociones de justicia, honor, decencia y respetabilidad. En este diálogo también es importante empezar a humanizar a las instituciones del Estado, como la policía, para poder entender las complejas relaciones que definían el quehacer policial y la idea de policía en el día a día.

\section{Agradecimientos}

A Susan Ramírez, Jeff Ferrell y al programa de postgrado de Texas Christian University.

\section{Referencias Citadas}

Aguirre, C.

2005 The Criminals of Lima and their Worlds: The Prison Experience, 1850-1935. Duke University Press, Durham.

Ballvé, A. (Bedel)

1900 "Las Policías chilenas. Su organización y funcionamiento. Impresiones de viaje”. Revista de Policía, III, 67: 311-326.

Barry, V.

2010 "Policía y reclutamiento. Hombres y organización policial en Buenos Aires, 1880-1910". Horizontes y Convergencias. Lecturas Históricas y Antropológicas sobre el Derecho (Julio). http://horizontesyc.com.ar/?p=3524 (12 enero 2013).
Caimari, L.

2017 While the City Sleeps: A History of Pistoleros, Policemen, and the Crime Beat in Buenos Aires before Perón. University of California Press, Oakland.

Del Águila, A.

1997 Callejones y Mansiones: Espacios de opinión pública y redes sociales y políticas en la Lima del 900 . Fondo Editorial de la Pontificia Universidad Católica del Perú, Lima.

Duffau, N.

2018 "La policía en la Provincia Oriental (1826-1838): Una construcción institucional entre el antiguo régimen y el orden republicano". Anuario IEHS 33, 1: 85-105. 
Foucault, M.

2005 Vigilar y Castigar. Nacimiento de la Prisión. Siglo Veintiuno Editores, México, D.F.

Galeano, D.

2011 “'Caídos en cumplimiento del deber'. Notas sobre la construcción del heroísmo policial". En Mirada (de) Uniforme: Historia y Crítica de la Razón Policial, editado por Diego Galeano y Gregorio Kaminsky, pp. 185-219. Teseo, Buenos Aires.

Huertas, L.

2015 Whistles and Clubs: The Institutional and Social History of the Police of Lima, 1890s-1910s. Tesis de Doctorado. AddRan College of Liberal Arts, Texas Christian University, Fort Worth.

Huertas, L.

2016 "Imagining Criminality: Race, Identity, and Crime in Peru, 1890-1920". En Voices of Crime: Constructing and Contesting Social Control in Modern Latin America, editado por Luz Huertas, Bonnie Lucero y Gregory Swedberg, pp. 51-73. The University of Arizona Press, Tucson.

Lira, $\mathrm{P}$.

1902 Manual para la policía. El Nacional, Lima.

Ludtke, A.

1995 The History of Everyday Life: Reconstructing Historical Experiences and Ways of Life. Princeton University Press, Princeton.

Mauch, C.

2017 Dizendo-se Autoridade: Policía e Policiais em Porto Alegre, 1866-1929. Editora Unisinos, São Leopoldo.

Ministerio de Gobierno y Policía

1896 Memoria que el Ministro Gobierno y Policía presenta á la Legislatura Ordinaria de 1896. Imprenta de El País, Lima.

Ministerio de Gobierno y Policía

1899 Memoria que el Ministro de Gobierno y Policía D. José María de la Puente presente a la Legislatura
Ordinaria de 1899. Imprenta y Librería de San Pedro, Lima.

Monahan, T.

2011 "Surveillance as cultural Practice". The Sociological Quarterly, 52, 4: 495-508.

Muñíz, P.

1892 Manual de policía aprobado por decreto supremo de 31 de mayo de 1892. Imprenta "La Equitativa", Lima.

Piccato, P.

2001a City of Suspects: Crime in Mexico City, 1900-1931. Duke University Press, Durham.

Piccato, $\mathrm{P}$

2001b "Cuidado con los Rateros: The Making of Criminals in Modern Mexico". En Crime and Punishment in Latin America: Law and Society since Late Colonial Times, editado por Ricardo D. Salvatore, Carlos Aguirre y Gilbert M. Joseph, pp. 233-272. Duke University Press, Durham.

Roodenburg, H. y P. Spierenburg

2004 Social Control Europe: 1500-1800. Ohio State University Press, Columbus.

Steege, P.; A. Stuart Bergerson, M. Healy y P. E. Swett

2008 "The History of Everyday Life: A Second Chapter". The Journal of Modern History, 80, 2: 358-378.

Scardaville, $\mathrm{M}$.

2000 "(Hapsburg) Law and (Bourbon) Order: State Authority, Popular Unrest, and the Criminal Justice System in Bourbon Mexico City". En Reconstructing Criminality in Latin America, editado por Carlos A. Aguirre y Robert Buffington, pp. 1-17. Scholarly Resources Inc., Wilmington.

Tirado, G.

1898 "Memoria de la Subprefectura e Intendencia de Policía de Lima. $1^{\circ}$ de Julio de 1897 á 30 de Junio de 1898". En Memoria del Sr. Prefecto del departamento de Lima 1898, editado por Federico Bresani, 1-144. Imprenta de El País, Lima.

\section{Notas}

1 Querella impuesta de oficio contra Manuel Moreno, acusado de robo.

2 De la perspectiva de Alltagsgeschichte se ha tomado en particular el énfasis acerca de lo ordinario y repetitivo y su relación con expresiones de agencia que tienden a (re) definir políticas, en este caso, de control social. Respecto de esta perspectiva, ver Alf Ludtke. 1995. The History of Everyday Life: Reconstructing Historical Experiences and Ways of Life. Princeton University Press, Princeton.

3 Solo en esa década hubo 20 cambios de ministro, siendo la mayoría de ellos -incluyendo los ministros interinosabogados o militares.

4 Esta cantidad de personal tendió a variar, aunque momentáneamente, durante períodos electorales.

5 Entre 1898 y 1899 Lima tuvo un aproximado de cincuenta y cuatro policías por diez mil habitantes, mientras que Buenos Aires tuvo aproximadamente cuarenta y seis, y Santiago de Chile, sesenta y seis por el mismo número de habitantes.

6 Para ello Muñiz publicó un manual en 1892 en forma de cuestionario en el que se explicaba de manera simplificada y sucinta la estructura y funciones de la policía. También promovió la realización de exámenes en las comisarías de Lima.

7 De manera similar a lo descrito por Nicolás Duffau (2018) para el caso de Montevideo en la primera mitad del siglo XIX, el quehacer policial estaba basado en una visión de orden y buen gobierno ordenados en dos áreas con responsabilidades y alcances distintos: la alta y la baja policía.

8 De 327 juicios de causas criminales analizados, 249 que se realizaron en 1890, 1891, 1895, 1900, 1905, y 1910 contienen información de los agentes -vecinos o policíasque iniciaron el arresto. En el análisis de estas fuentes se tomó en cuenta la información del agraviado, así como de la persona que solicitó la presencia de la policía. El tipo de oficio (desempleados, jornaleros, aprendices, lavanderas, cargadores, albañiles, empleados domésticos, vendedores ambulantes, costureras y sastres, ladrilleros, choferes, etc.), el nivel educativo (saber leer o escribir, saber firmar), el tipo de vivienda y su ubicación, así como el tipo de testigos de parte-en el caso de haberlos-fueron tomados en cuenta para definir la procedencia e identidad de la persona agraviada y de la que solicitó el arresto. Un análisis más profundo 
de estas fuentes y factores se encuentra en la disertación doctoral de la autora (Huertas 2015).

9 Este reconocimiento, por ejemplo, muestra una relación entre la policía y los ciudadanos muy distinta a la planteada por Michel Foucault en su análisis acerca del uso de las lettres de cachet en Francia, el que interpreta como un instrumento del aparato disciplinario que impuso una visión de orden sobre la sociedad (Foucault 2005: 2017-218).

10 Énfasis añadido por la autora.

11 En Callejones y Mansiones Alicia del Águila menciona que los callejones de la ciudad "están compuestos por cuartos uno, o por lo general, a ambos lados de un pasadizo usualmente estrecho, cerrado por una pared en el extremo opuesto que da a la calle. Uno o dos caños debían proporcionar agua a cientos de personas. Cuando el pasadizo se ramificaba en el interior, se llamaba solar".

12 La Sección de Vigilancia fue creada en 1873 bajo el nombre de Sección de Policía Preventiva. Esta sección tenía su propio personal y respondía directamente al intendente, mientras que los guardias de la ciudad recibían órdenes de los comisarios.

13 Los recibos de pignoración eran boletas entregadas por la casa de empeño detallando los artículos dejados para su venta, así como el nombre de la persona que los entregó y la cantidad de dinero por la que se empeñaron dichos artículos. 
